\title{
Carbon sequestration through enhanced weathering processes on Trictum aestivum production in an acidic and an alkaline soil: yield and $\mathrm{N}_{2} \mathrm{O}$ emissions co-benefits.
}

\author{
SÍLVIA POBLADOR, ARTHUR VIENNE, ERIK \\ VERBRUGGEN AND SARA VICCA
}

University of Antwerp

Presenting Author: spoblador@gmail.com

Enhanced weathering of silicate minerals (EW) is a promising carbon dioxide removal (CDR) method that can be associated with multiple co-benefits for crop production when spreading silicate minerals on arable soils. Moreover, changes in agricultural management practices to enhance soil organic carbon (C) sequestration while maintaining crop productivity (i.e. not competing for land surface) are a key opportunity to reduce the impact of humans on the environment, reducing greenhouse gas fluxes to the atmosphere and nutrient leaching to aquatic ecosystems, without compromising food and soil security. Yet, these co-benefits of EW on agricultural practices are still poorly understood. Among others, EW can increase crop yields, restore base cations (e.g. $\mathrm{Mg}, \mathrm{Ca}$ ) and micro- and macronutrient (e.g. Si, $\mathrm{Zn}$ ) stocks, as well as reduce $\mathrm{N}_{2} \mathrm{O}$ and nitrate $\left(\mathrm{NO}_{3}{ }^{-}\right)$losses due to increases in soil $\mathrm{pH}$ and facilitation of a complete denitrification. In order to verify these potential co-benefits for crop production, winter wheat (Triticum aestivum) was grown in 20 mesocosms following 4 treatments: acid soil $(\mathrm{pH} \sim 5)$ without basalt addition, acid soil with basalt addition (50 tones ha $\left.{ }^{-1}\right)$, alkaline soil $(\mathrm{pH} \sim 7)$ without basalt addition, and alkaline soil with basalt addition. The results of the experiment allowed to quantify soil $\mathrm{C}$ sequestration in acid and alkaline soils through $\mathrm{EW}$, as well as the potential long term $\mathrm{C}$ sequestration by PHREEQC modelling. Furthermore, the co-benefits of EW on crop biomass production, cations and nutrients available for plants, effects on soil nitrogen cycle and reduction of soil $\mathrm{N}_{2} \mathrm{O}$ emissions were studied. Overall, our results showed higher $\mathrm{C}$ sequestration and co-benefits for the acid soil mesocosms, suggesting that EW could be mutually beneficial for soil $\mathrm{C}$ sequestration and winter wheat yield, as agricultural soils are typically acid and nutrient poor. 